\title{
Distribution Loss Allocation Methods Assessment Under Electricity Market Environment
}

\author{
P. M. De Oliveira-De Jesús, Member, IEEE, and M. T. Ponce de Leão, Member, IEEE
}

\begin{abstract}
Under real-time or day-ahead pool-based electricity markets, the implementation of the distribution loss allocation procedures implies an access-pricing framework based on halfhour or hour locational prices. For each consumer and distributed generator it is required to apply an additional charge in the energy price in order to cover the cost of active losses. Since every allocation procedure modifies the locational prices in a different way, the initial market equilibrium point is altered and some form of cross-subsidies appears among market agents affecting the net social welfare and the network remuneration. The regulator should address the economical impact of each allocation method in order to ensure a non-discriminatory access to the network and guarantee revenue reconciliation of losses. This paper contributes to regulator assessment introducing a novel analysis of the impact of each loss allocation procedure based on the social welfare theory and explicitly considering the price elasticity of demand. The methodology was tested in two distribution test systems. ${ }^{1}$
\end{abstract}

Index Terms - distribution loss allocation, distribution, distributed generation, embedded generation, economics.

\section{INTRODUCTION}

$\mathbf{U}$ NDER ongoing restructuring process, electric distribution activities remains as monopoly and traditional regulatory schemes based on Cost of Service/Rate of Return (CoS/RoR) regulation have been substituted by a new regulatory frameworks as Performance Based Ratemaking (PBR) regulations. These incentive regulation approaches are established to encourage economic efficiency, proposing an open and nondiscriminatory access to the networks. Unfortunately, an open access policy must be made through an imperfect delivery network that produces power losses. In consequence, these power losses must be fairly allocated among the all distributed generators and consumers. Losses are nonlinear functions of line flows and it is difficult to define the responsibility of each market agent in global power losses.

Several and different methods for power loss cost allocation have been proposed in the literature, mainly in transmission systems [1]. Nevertheless, a lack of methods applied to distribution systems is observed. Generally, losses at distribution level were considered as an additional load and therefore allocated among all consumers using average values [2].

Manuscript received Oct. 15, 2004. This work was supported by the Fundação para a Ciência e a Tecnologia Portugal Grant SFRHBD8410/2002 and Value of Non-Utility Sources Project VENUS/POCTIESE-47883/2002.

P. M. De Oliveira-De Jesús and M. T. Ponce de Leão are with Electrical and Computer Department of Faculdade de Engenharia da Universidade do Porto (FEUP), and Instituto de Engenharia de Sistemas e Computadores (INESC Porto), Dr. Roberto Frias, 378 4200-465 Porto Portugal (e-mail: pdeoliv@fe.up.pt)
However, distributed generation (DG) has faced a heavy growth in the recent years forcing the development of new allocation procedures. Commonly, these new procedures have been adapted from methodologies proposed to allocate losses in transmission systems. These methods could be divided into five families as seen in Table I:

TABLE I

Distribution COST LOSS ALLOCATION PROCEDURES

\begin{tabular}{ll}
\hline Family & Procedures \\
\hline Roll-in-embedded & $\begin{array}{l}\text { Postage stamp or Pro Rata (PR) [2-3] } \\
\text { MW-mile [3] }\end{array}$ \\
Tracing Based & Proportional Sharing (PS) [4] \\
Circuit Based & Zbus [5] \\
Marginal & Marginal Loss Coefficients (MLC) [6] \\
& Reconciled Marginal Loss Factors (RMLC) [7-9] \\
Avoided Cost Loss & Postage Stamp or Pro Rata (Avoided-PR) [7] \\
& Proportional Sharing (Avoided-PS) [8] \\
\hline
\end{tabular}

In the roll-in-embedded procedures, losses are globally assigned to generators and consumers, usually 50:50\% using a postage stamp or pro rata approach based on average values [2-3]. The power flow based MW-mile procedure is based on the extent of use of distribution network by all generators and demands [3]. The Proportional sharing procedures assume that power injections are proportionally shared among the outflows of each bus [4]. This analysis is made in a branch basis, taking into account the allocation of cross terms of losses. Results always derive in positive charges and it is not possible to allocate losses to producers and loads at same time. The Circuit based or Zbus loss allocation model distributes the system losses in a natural form using the real part of the inverse of admittance matrix [5]. The Marginal procedures are based on the computation of loss penalty factors - also called marginal loss coefficients - obtained from a converged AC power flow [6]. Many authors consider that marginal approach produces an efficient performance and competitive prices. However, due to the network nonlinearities, these prices must be normalized in order to obtain Reconciled Marginal Loss Coefficients and avoid over recovery of losses [7-9]. Recently, Avoided cost procedures have been proposed based on the allocation of the entire costs to consumers disregarding the influence distributed sources using a postage stamp approach [3] or the proportional sharing principle [11] and reallocating the avoided or produced losses among all generators.

Present energy markets are under ongoing restructuring tasks in order to introduce real-time or day a-head electricity prices and encourage the responsiveness of demand in the wholesale market [12]. In this scenario, when a particular allocation method is applied, as result of short-term elasticity [14], the market equilibrium point is shift to a new equilibrium point and 
some form of cross-subsidies appears among market agents affecting the net social welfare and network remuneration.

Regulatory agencies may address the economical impact of allocation methods in order to ensure a non-discriminatory access to the network and guarantee revenue reconciliation of losses of the distribution utility. This paper tries to contribute to regulatory assessment introducing a methodology to evaluate the impact of each distribution loss allocation procedure in realtime energy markets based in the social welfare theory [13][14]. The proposed methodology is applied in two steps:

a) Loss allocation at given market equilibrium point for each procedure and considering different levels of penetration of distributed generation into distribution networks.

b) Computation of new equilibrium points for each allocation procedure and distributed generation penetration levels, taking into account some elasticity at demand-side in order to evaluate social welfare and network remuneration level for comparison purposes.

The methodology has been tested in an illustrative 3-bus network and a real 28-bus distribution system with two distributed producers.

\section{Distribution LoSS AllocAtion PROCEDURES}

A loss allocation procedure distributes the total active power losses $L$ among all distributed generators and consumers in agreement with the following relationship:

$$
L=\sum_{i=1}^{n} L_{G i}+\sum_{i=1}^{n} L_{D i}
$$

where

$L_{G i} \quad$ active power loss allocated to generators of bus $i$;

$L_{D i} \quad$ active power loss allocated to demands of bus $i$.

As general rule, it is defined that positive losses signify that market agents (producers and consumers) are charged by power losses. Conversely, negative losses mean that market agents must be rewarded by power losses.

It is must be stressed that unlike transmission methods, all distribution loss allocation procedures require a reference bus previously defined in the interconnection point of distribution network with the transmission system. In these reference buses no loss compensation is done. Losses are assigned only to consumers and distributed generators.

In this section, a detailed description of each methodology applied in this paper is presented.

\section{A. Roll-in-embedded Procedures}

\section{- Postage Stamp or Pro Rata (PR)}

The postage stamp or pro rata [2-3] procedure uses average values to allocate $50 \%$ of losses to the demands and $50 \%$ to generators, that is:

$$
\begin{aligned}
& L_{G i}=50 \% \times L \times P_{G i} / P_{G}, \quad K_{G i}=0.5 L P_{G} \quad i, \ldots, n \\
& L_{D i}=50 \% \times L \times P_{D i} / P_{D}, \quad K_{D i}=0.5 L P_{D} \quad i, \ldots, n
\end{aligned}
$$

- Power Flow based MW-mile (MW-mile)

The MW-mile procedure [3] allocates $50 \%$ of losses to the demands and $50 \%$ to generators and it is based on the extent of use of distribution network. Then, the allocation charge by use

of the network $T$ applied to each demand and generator is expressed as:

$$
\begin{aligned}
& T_{D i}=\sum_{k=1}^{m} F_{D i k} l_{k} \\
& T_{G i}=\sum_{k=1}^{m} F_{G k i} l_{k}
\end{aligned}
$$

where,

$F_{D k j} \quad$ power flow in branch k due to demand $i$ (MW)

$F_{G k j} \quad$ power flow in branch $\mathrm{k}$ due to generator $i$ (MW)

$l_{k} \quad$ length of branch $\mathrm{k}$ (miles)

$m \quad$ number of branches

Losses allocated are given by:

$$
\begin{aligned}
L_{D i} & =50 \% L T_{D i} / \sum_{j=1}^{m} T_{D j} \quad i, \ldots, n \\
L_{G i} & =50 \% L T_{G i} / \sum_{j=1}^{m} T_{G j} \quad i, \ldots, n
\end{aligned}
$$

\section{B. Proportional Sharing Procedure (PS)}

Proportional sharing methods [5] are based on the tracing of gross line flows. This method assumes that the system is fed by the actual generation. Generation dispatch remains unchanged and nodal demands must be slightly modified in order to accomplish Kirchoff's laws. However, it is not possible to allocate losses to generators and demands at the same time. Generally, upstream looking algorithm is applied to allocate $50 \%$ power losses between generators and a downstream looking algorithm to allocate the other $50 \%$ of power losses among demands.

\section{1) Downstream looking algorithm}

The total power gross flow $P_{i}^{\text {gross }}$ (i.e. the sum of all outflows at bus $i$ ) may be expressed as:

$$
P_{i}^{\text {gross }}=P_{G i}+\sum_{j \in \alpha_{i}^{\text {down }}} \delta_{j i} P_{j}^{\text {gross }} \delta_{j i}=P_{j i}^{\text {gross }} / P_{j}^{\text {gross }} i=1, \ldots, n
$$

where,

$\sum_{j \in \alpha_{i}^{\text {down }}} \delta_{j i} P_{j}^{\text {gross }} \quad$ power flow leaving bus $i$;

$\alpha_{i}^{\text {down }} \quad$ set of buses receiving power from bus $i$;

Equation (8) constitutes a system of linear equations written as:

$$
\boldsymbol{A}_{d} \boldsymbol{P}^{\text {gross }}=\boldsymbol{P}_{G}
$$

Then, gross demand at bus $i$, is expressed:

$$
P_{G i}^{\text {gross }}=\frac{P_{G i}}{P_{i}} \sum_{j=1}^{n}\left[A_{d i j}^{-1}\right] P_{D j} \quad i=1, \ldots, n
$$

and power losses allocated to demand are:

$$
L_{G i}=P_{G i}^{g r o s s}-P_{G i} \quad i=1, \ldots, n
$$

\section{2) Upstream looking algorithm}

The total power gross flow $P_{i}^{\text {gross }}$ (i.e. the sum of all inflows at bus $i$ ) may be expressed as:

$$
P_{i}^{\text {gross }}=P_{G i}+\sum_{j \in \alpha_{i}^{u i}} \delta_{j i} P_{j}^{\text {gross }} \delta_{j i}=P_{j i}^{\text {gross }} / P_{j}^{\text {gross }} i=1, \ldots, n
$$

where,

$\sum_{j \in \alpha_{i}^{\text {up }}} \delta_{j i} P_{j}^{\text {gross }}$

$\alpha_{i}^{u p}$ power flow reaching bus $i$ from lines connected it; set of buses from which power flows toward bus $i$; 
Equation (12) constitutes a system of equations written as:

$$
\boldsymbol{A}_{u} \boldsymbol{P}^{\text {gross }}=\boldsymbol{P}_{G}
$$

Then, gross demand at bus $i$, is expressed:

$$
P_{D i}^{\text {gross }}=\frac{P_{D i}}{P_{i}} \sum_{j=1}^{n}\left[A_{u i j}^{-1}\right] P_{G j} \quad i=1, \ldots, n
$$

and power losses allocated to demand are:

$$
L_{D i}=P_{D i}^{\text {gross }}-P_{D i} \quad i=1, \ldots, n
$$

\section{Circuit Based Allocation (Zbus)}

The circuit based loss allocation model [5] distributes the system losses $L$ among $n$ buses of the network according to:

$$
L=\sum_{i=1}^{n} L_{i}
$$

The $L_{i}$ components are obtained from the real part of the inverse of admittance matrix $Y=G+j B$, Zbus $=Y^{1}=R+j X$ using the following general expression:

$$
L_{i}=\mathfrak{R}\left[I_{i}^{*}\left(\sum_{j=1}^{n} R_{i j} I_{j}\right)\right] \quad i=1, \ldots, n
$$

where, $I_{i}=\left(S_{i}^{*} / V_{i}^{*}\right)$.

In general, if a given bus $i$ has both generation $P_{G i}$ and demand $P_{D i}$, the allocation loss component $L_{i}$ can be further assigned in a pro rata manner.

$$
L_{G i}=\left(1-\gamma_{i}\right) L_{i}, L_{D i}=\gamma_{i} L_{i} \quad i=1, \ldots, n
$$

where,

$$
\gamma_{i}=P_{D i} / P_{G i}+P_{D i} \quad i=1, \ldots, n
$$

\section{Marginal Loss Cost Procedure (MLC)}

Under incremental analysis, power losses can be allocated to producers and consumers simultaneously through Marginal Loss Coefficients (MLCs) that measure the change in power losses due to the incremental change in power injections in each bus of the network:

$$
M L C_{i}^{P}=\frac{\partial L}{\partial\left(P_{G i}-P_{D i}\right)} \quad M L C_{i}^{Q}=\frac{\partial L}{\partial\left(Q_{G i}-Q_{D i}\right)}
$$

The standard chain rule is applied in the calculation of MLCs using intermediate variables, voltages and angles obtained from a converged AC power flow [6]:

$$
\left[\frac{M L C_{A C}^{P}}{M L C_{A C}^{Q}}\right]=\left[\begin{array}{cccc:cccc}
\frac{\partial P_{1}}{\partial \theta_{1}} & \frac{\partial P_{2}}{\partial \theta_{1}} & \cdots & \frac{\partial P_{n}}{\partial \theta_{1}} & \frac{\partial Q_{1}}{\partial \theta_{1}} & \frac{\partial Q_{2}}{\partial \theta_{1}} & \cdots & \frac{\partial Q_{n}}{\partial \theta_{1}} \\
\frac{\partial P_{1}}{\partial \theta_{2}} & \frac{\partial P_{2}}{\partial \theta_{2}} & \cdots & \frac{\partial P_{n}}{\partial \theta_{2}} & \frac{\partial Q_{1}}{\partial \theta_{2}} & \frac{\partial Q_{2}}{\partial \theta_{2}} & \cdots & \frac{\partial Q_{n}}{\partial \theta_{2}} \\
\vdots & \vdots & \ddots & \vdots & \vdots & \vdots & \ddots & \vdots \\
\frac{\partial P_{1}}{\partial \theta_{n}} & \frac{\partial P_{2}}{\partial \theta_{n}} & \cdots & \frac{\partial P_{n}}{\partial \theta_{n}} & \frac{\partial Q_{1}}{\partial \theta_{1}} & \frac{\partial Q_{1}}{\partial \theta_{1}} & \cdots & \frac{\partial Q_{1}}{\partial \theta_{1}} \\
\hdashline \frac{\partial P_{1}}{\partial V_{1}} & \frac{\partial P_{2}}{\partial V_{1}} & \cdots & \frac{\partial P_{n}}{\partial V_{1}} & \frac{\partial Q_{1}}{\partial V_{1}} & \frac{\partial Q_{2}}{\partial V_{1}} & \cdots & \frac{\partial Q_{n}}{\partial V_{1}} \\
\frac{\partial P_{1}}{\partial V_{2}} & \frac{\partial P_{2}}{\partial V_{2}} & \cdots & \frac{\partial P_{n}}{\partial V_{2}} & \frac{\partial Q_{1}}{\partial V_{2}} & \frac{\partial Q_{2}}{\partial V_{2}} & \cdots & \frac{\partial Q_{n}}{\partial V_{2}} \\
\vdots & \vdots & \ddots & \vdots & \vdots & \vdots & \ddots & \vdots \\
\frac{\partial P_{1}}{\partial V_{n}} & \frac{\partial P_{2}}{\partial V_{n}} & \cdots & \frac{\partial P_{n}}{\partial V_{n}} & \frac{\partial Q_{1}}{\partial V_{n}} & \frac{\partial Q_{2}}{\partial V_{n}} & \cdots & \frac{\partial Q_{n}}{\partial V_{n}}
\end{array}\right]^{-1}\left[\begin{array}{c}
\frac{\partial L}{\partial \theta_{1}} \\
\vdots \\
\frac{\partial L}{\partial \theta_{n}} \\
\hdashline \frac{\partial V_{1}}{\partial V_{n}} \\
\frac{\partial L}{\partial V_{2}} \\
\vdots \\
\frac{\partial L}{\partial V_{n}}
\end{array}\right]
$$

The general system of linear equations is solved eliminating the columns and rows correspondent to slack and PV buses: $M L C^{P}{ }_{s l}=M L C^{Q}{ }_{s l}=M L C_{p v}^{Q}=0$ and entries of the transpose of Jacobean and the right-hand vector are:

$$
\begin{aligned}
& \frac{\partial P_{i}}{\partial \theta_{j}}=V_{i} V_{j}\left[G_{i j} \sin \left(\theta_{i}-\theta_{j}\right)-B_{i j} \cos \left(\theta_{i}-\theta_{j}\right)\right] \\
& \frac{\partial P_{i}}{\partial \theta_{i}}=-B_{i i} V_{i}^{2}-\sum_{j=1}^{n} V_{i} V_{j}\left[G_{i j} \sin \left(\theta_{i}-\theta_{j}\right)-B_{i j} \cos \left(\theta_{i}-\theta_{j}\right)\right] \\
& \frac{\partial P_{i}}{\partial V_{j}}=V_{i}\left[G_{i j} \cos \left(\theta_{i}-\theta_{j}\right)+B_{i j} \sin \left(\theta_{i}-\theta_{j}\right)\right] \\
& \frac{\partial P_{i}}{\partial V_{i}}=G_{i i} V_{i}+\sum_{j=1}^{n} V_{j}\left[G_{i j} \cos \left(\theta_{i}-\theta_{j}\right)+B_{i j} \sin \left(\theta_{i}-\theta_{j}\right)\right] \\
& \frac{\partial Q_{i}}{\partial \theta_{j}}=-V_{i} V_{j}\left[G_{i j} \cos \left(\theta_{i}-\theta_{j}\right)+B_{i j} \sin \left(\theta_{i}-\theta_{j}\right)\right] \\
& \frac{\partial Q_{i}}{\partial \theta_{i}}=-G_{i i} V_{i}^{2}+\sum_{j=1}^{n} V_{i} V_{j}\left[G_{i j} \cos \left(\theta_{i}-\theta_{j}\right)+B_{i j} \sin \left(\theta_{i}-\theta_{j}\right)\right] \\
& \frac{\partial Q_{i}}{\partial V_{j}}=V_{i}\left[G_{i j} \sin \left(\theta_{i}-\theta_{j}\right)-B_{i j} \cos \left(\theta_{i}-\theta_{j}\right)\right] \\
& \frac{\partial Q_{i}}{\partial V_{i}}=-B_{i i} V_{i}+\sum_{j=1}^{n} V_{j}\left[G_{i j} \sin \left(\theta_{i}-\theta_{j}\right)-B_{i j} \cos \left(\theta_{i}-\theta_{j}\right)\right] \\
& \frac{\partial L}{\partial \theta_{i}}=2 \sum_{j=1}^{n} V_{i} V_{j} G_{i j} \sin \left(\theta_{i}-\theta_{j}\right) \\
& \frac{\partial L}{\partial V_{i}}=2 \sum_{j=1}^{n} G_{i j}\left[V_{i}-V_{j} \cos \left(\theta_{i}-\theta_{j}\right)\right]
\end{aligned}
$$

First computations of losses allocated to generators and demands connected to bus $i$ are, respectively:

$$
\begin{array}{cc}
L_{G i}=-P_{G i} \cdot M L C_{i}^{P} & i=1, \ldots, n \\
L_{D i}=P_{D i} \cdot M L C_{i}^{P} & i=1, \ldots, n
\end{array}
$$

\section{E. Reconciled Marginal Loss Cost Allocation (RMLC)}

However, as result of nonlinearity of losses the sum of allocated losses does not match with the actual losses of the system.

$$
\sum_{i=1}^{n} L_{G_{i}}+\sum_{i=1}^{n} L_{D_{i}}>L
$$

where

$$
L=\frac{1}{2} \sum_{i=1}^{n} \sum_{j=1}^{n} G_{i j}\left[V_{i}^{2}+V_{j}^{2}-2 V_{i} V_{j} \cos \left(\theta_{i}-\theta_{j}\right)\right]
$$

Therefore, losses allocated must be normalized [7-9] through a reconciliation factor $k_{o}$.

$$
\begin{array}{ll}
L_{G i}=P_{G i} \cdot k_{o} \cdot M L C_{i}^{P} & i=1, \ldots, n \\
L_{D i}=-P_{D i} \cdot k_{o} \cdot M L C_{i}^{P} & i=1, \ldots, n
\end{array}
$$

where

$$
k_{o}=\frac{L}{\sum_{i=1}^{n} L_{G_{i}}+\sum_{i=1}^{n} L_{D_{i}}}
$$

\section{F. Avoided Cost Loss Procedures (Avoid PR and Avoid PS)}

More recently, another procedure has been proposed based on the concept of avoided cost [10-11]. This approach consists in allocating the entire losses to consumers disregarding the influence of distributed generators using the pro rata (AvoidedPR) approach [10] or the proportional sharing principle (Avoided-PS) [11]. Afterwards, the avoided or formed losses are reallocated among distributed generators using the same allocation procedure. 


\section{SOCIAL WELFARE ANALYSIS}

The key idea introduced in this article is that an energy market requires some elasticity at demand-side to be efficient [1]. Thus, if a given cost allocation procedure is applied, due to the elasticity of demand the equilibrium point is altered affecting economic variables as the distribution network remuneration, the production and consumer surplus and therefore the global social welfare [13].

Under real-time or day-ahead markets, an adequate price framework to allocate power losses are based on hourly locational prices. For each consumer and producer it is required to apply an additional charge in the energy cost in order to cover the cost of active losses. For each procedure $k$, new prices could be computed and applied to consumers and producers using the following expressions:

$$
\begin{aligned}
& \rho_{D i}^{k}=\lambda_{\text {syst }}\left(1+L_{D i}^{k} / P_{D i}^{k}\right) \quad i=1, \ldots, n ; k=0, \ldots, 8 \\
& \rho_{G i}^{k}=\lambda_{\text {syst }}\left(1-L_{G i}^{k} / P_{G i}^{k}\right) \quad i=1, \ldots, n ; k=0, \ldots, 8
\end{aligned}
$$

where, $\lambda_{\text {syst }}$ is the system market price.

The new prices produce an elastic response at demand-side, reaching a new consumption level given by the following linear function:

$$
\rho_{D i}^{k}=\rho_{D i}^{\max }-m_{D i} P_{D i}^{k} \quad i=1, \ldots, n ; k=0, \ldots, 8
$$

where $\rho_{D i}^{\max }$ is the maximum price willing to pay by load $i$ and $m_{D i}$ is the slope of demand curve obtained form specified price elasticity of demand $\varepsilon_{D i}$ at given operation point $\left(\rho_{D i}^{o}, P_{D i}^{o}\right)$.

$$
\varepsilon_{D i}=\frac{\Delta P_{D} / P_{D i}^{0}}{\Delta \rho / \rho_{D i}^{0}}=\frac{1}{m_{D i}} \cdot \frac{\rho_{D i}^{0}}{P_{D i}^{0}} \quad i, \ldots, n
$$

Subsequently, a power flow must be performed in order to obtain the power losses incurred in the system due to changes at demand side produced by each allocation method.

Finally, in agreement with the economic theory [14][15] for every new equilibrium point, social welfare parameter are computed as the sum of producer surplus and consumer surplus and distribution network remuneration as the difference between the network revenues and expenses:

$$
\begin{gathered}
\overbrace{S W^{k}=\sum_{i=1}^{n}[\underbrace{B_{i}\left(P_{D i}^{k}\right)}_{\text {benefits }}-\underbrace{\rho_{D i}^{k} P_{D i}^{k}}_{\text {Expenses }}]}^{\text {CONSUMER SURPLUS }}+\overbrace{\sum_{i=1}^{n}[\underbrace{\rho_{G i}^{k} P_{G i}^{k}}_{\text {Revenues }}-\underbrace{C_{i}\left(P_{G i}^{k}\right)}_{\text {Costs }}]}^{\text {PRODUCER SURPLUS }} \\
N R^{k}=\underbrace{\sum_{i=1}^{n} \rho_{D i}^{k} P_{D i}^{k}}_{\text {Revenues }}-\underbrace{\text { Expenses }}_{\sum_{i=1}^{n} \rho_{G i}^{k} P_{G i}^{k}}
\end{gathered}
$$

Variable production costs of distributed generators are expressed in a quadratic form

$$
C_{i}\left(P_{G i}\right)=a_{i} P_{G i}+b_{i} P_{G i}^{2} \quad i, \ldots, n
$$

Consumer benefit is obtained from a linear demand curve given in equation (41) applying the general definition [14]:

$$
B_{i}\left(P_{D i}\right)=\int \rho_{D i}\left(P_{D i}\right) \cdot d P_{D i}=\rho_{D i}^{\max } P_{D i}-\frac{1}{2 m_{D i}} P_{D i}^{2} i, \ldots, n
$$

\section{CASE StUdy}

The proposed methodology has been tested in two cases. Firstly, in an illustrative three-bus test network and finally a 28bus distribution system with two distributed generators.

\section{A. Case $N^{\circ}$ 1: Three-bus network}

In Fig. 1 the one-line diagram of a three-bus test network is presented. A 5MW-rated wind generator is connected to bus 2 . Load demands connected to bus 2 and 3 have 2MW and 3.5MW, respectively. Line data is given in per unit considering $\mathrm{S}_{\mathrm{BASE}}=10 \mathrm{MVA}$ and $\mathrm{V}_{\mathrm{BASE}}=10 \mathrm{kV}$. Bus 1 corresponds with the interconnection bus with the transmission system.

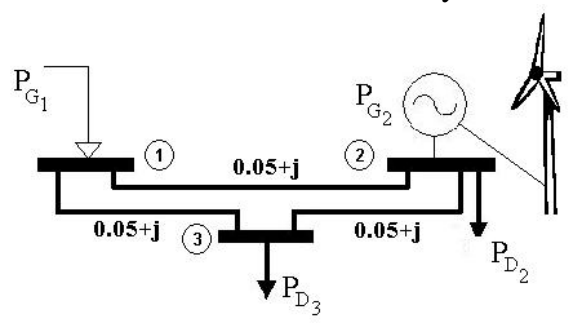

Fig. 1. Three bus test network

\section{.- Market Equilibrium Point}

At given hour, $P_{G 1}$ represent the energy purchased in MW in the wholesale market at clearing or system market price that is preset in $\lambda_{\text {sys }}=10 \$ / \mathrm{MWh}$. Similarly, power injected by the distributed generator $P_{G 2}$ is remunerated at the same clearing market price $\lambda_{\text {sys. }}$. Since fuel costs are zero and operating expenses are low mall, it is considered that marginal cost of wind energy is low and therefore negligible. In addition, market regulation imposes that distributed generators must offer reactive compensation in order to guarantee nominal voltage at his own busbar. The initial operation point is fixed considering that consumers were charged at the competitive price results obtained from MLC approach at load peak values $P_{D}^{0}=2 \mathrm{MW}$ and $P_{D 3}^{0}=3.5 \mathrm{MW}$. Thus, it is assumed that load demands are linear elastic with price elasticity equal to -0.5 . This means that at equilibrium point the variation of $10 \%$ in price leads in a change of $5 \%$ in consumption.

\section{.- Power Loss Allocation}

As renewable production is non-dispatchable and based on the discontinuous and stochastic nature of its primary sources, -in this case, wind - a penetration level dependent on natural resource for each generator $i$ is defined in order to be used in the assessment of all allocation procedures:

$$
\eta_{i}=100 \% P_{G i} / \sum_{i=1}^{n} P_{D i}
$$

Table II and Fig. 2 show the actual and avoided power losses to be allocated by each procedure as function of different penetration levels.

TABLE II

ACTUAL AND AVOIDED POWER LOSSES

\begin{tabular}{l|c|c|c}
\hline \multirow{2}{*}{$\begin{array}{l}\text { Losses } \\
(\mathrm{kW})\end{array}$} & \multicolumn{3}{|c}{ DG penetration level $\eta(\%)$} \\
\cline { 2 - 4 } & $10 \%$ & $50 \%$ & $90 \%$ \\
\hline Actual & 68.00 & 35.22 & 36.46 \\
\cline { 2 - 4 } $\begin{array}{l}\text { Without DG } \\
\text { Avoided }\end{array}$ & 84.46 & 84.46 & 84.46 \\
\cline { 2 - 4 } & 16.46 & 49.24 & 48.00 \\
\hline
\end{tabular}


The power losses computed disregarding the influence of the distributed generator are $84.46 \mathrm{~kW}$. It is observed that minimum power losses were reached when DG penetration level is $69 \%$.

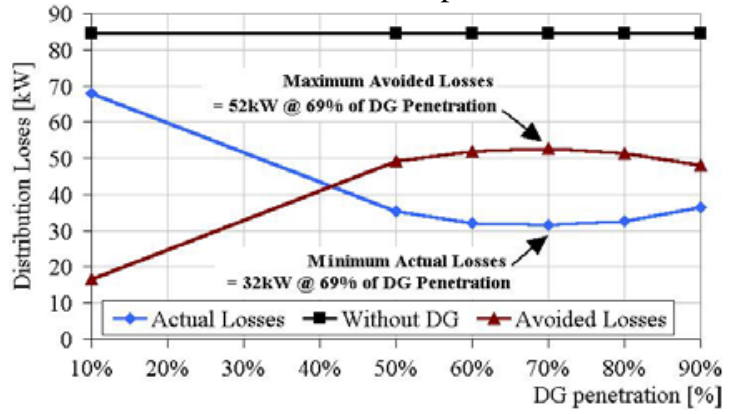

Fig. 2. Distribution Losses as function of DG penetration level $\left(\eta_{2}\right)$.

Table III provides the percentage of total losses allocated to generators and loads -calculated as $100 \% \times L_{G i} / L$ and $100 \% \times L_{D i} / L-$ using three penetration levels for the eightcompared procedures: 10,50 and $90 \%$ respectively.

TABLE III

Percentage of Losses Allocated Using the Eight COMPARED LOSS ALLOCATION PROCEDURES

\begin{tabular}{|c|c|c|c|c|c|c|c|c|c|}
\hline \multirow{4}{*}{$\begin{array}{l}\text { Loss } \\
\text { Allocation } \\
\text { Procedure }\end{array}$} & \multicolumn{9}{|c|}{ Losses Allocated (\%) } \\
\hline & \multicolumn{9}{|c|}{ DG penetration level $\eta(\%)$} \\
\hline & \multicolumn{3}{|c|}{$10 \%$} & \multicolumn{3}{|c|}{$50 \%$} & \multicolumn{3}{|c|}{$90 \%$} \\
\hline & $\mathrm{P}_{\mathrm{G} 2}$ & $\mathrm{P}_{\mathrm{D} 2}$ & $\mathrm{P}_{\mathrm{D} 3}$ & $\mathrm{P}_{\mathrm{G} 2}$ & $\mathrm{P}_{\mathrm{D} 2}$ & $\mathrm{P}_{\mathrm{D} 3}$ & $\mathrm{P}_{\mathrm{G} 2}$ & $\mathrm{P}_{\mathrm{D} 2}$ & $\mathrm{P}_{\mathrm{D} 3}$ \\
\hline$\overline{M L C}$ & $-18.6 \%$ & $67.7 \%$ & $161.2 \%$ & $-54.8 \%$ & $39.9 \%$ & $223.4 \%$ & $110.0 \%$ & $-44.4 \%$ & $142.0 \%$ \\
\hline RMLC & $-8.9 \%$ & $32.2 \%$ & $76.7 \%$ & $-26.3 \%$ & $19.1 \%$ & $107.2 \%$ & $53.0 \%$ & $-21.4 \%$ & $68.4 \%$ \\
\hline ZBUS & $64.0 \%$ & $4.4 \%$ & $31.6 \%$ & $38.6 \%$ & $1.2 \%$ & $60.2 \%$ & $30.2 \%$ & $11.6 \%$ & $58.2 \%$ \\
\hline PR & $50.0 \%$ & $18.2 \%$ & $31.8 \%$ & $50.0 \%$ & $18.2 \%$ & $31.8 \%$ & $50.0 \%$ & $18.2 \%$ & $31.8 \%$ \\
\hline MW-mile & $50.0 \%$ & $20.8 \%$ & $29.2 \%$ & $50.0 \%$ & $14.6 \%$ & $35.4 \%$ & $50.0 \%$ & $24.6 \%$ & $25.4 \%$ \\
\hline PS & $50.0 \%$ & $13.0 \%$ & $37.0 \%$ & $50.0 \%$ & $1.9 \%$ & $48.1 \%$ & $50.0 \%$ & $0.0 \%$ & $50.0 \%$ \\
\hline Avoid-PR & $-24.5 \%$ & $45.7 \%$ & $80.0 \%$ & $-139.8 \%$ & $87.2 \%$ & $152.6 \%$ & $-131.4 \%$ & $84.1 \%$ & $147.1 \%$ \\
\hline Avoid-PS & $-24.5 \%$ & $40.3 \%$ & $85.5 \%$ & $-139.8 \%$ & $76.8 \%$ & $163.0 \%$ & $-131.4 \%$ & $74.0 \%$ & $157.2 \%$ \\
\hline
\end{tabular}

The results show that marginal allocation MLC derives in volatile values producing an over recovery of power losses for all DG penetration levels. For instance, when DG penetration level is equal to $50 \%$, losses allocated to consumers and producers are $-54.8 \%+39.9 \%+223.4 \%=208.5 \%$. When the DG penetration level is low (10\%) and marginal approaches are applied, it is observed that generator 2 is rewarded by his contribution in loss reduction and both loads must pay for their contribution in loss increase. On the contrary, when DG penetration is high (90\%) generator 3 and load 3 must pay for formed losses and load 2 is rewarded by his contribution in loss reduction. Also, Zbus, PR, MW-mile, and PS approaches, derive in positive charges. This means that loads and generators were penalized by formed power losses. PR, MW-mile and PS approach $50 \%$ of power losses were allocated to generator 2 .

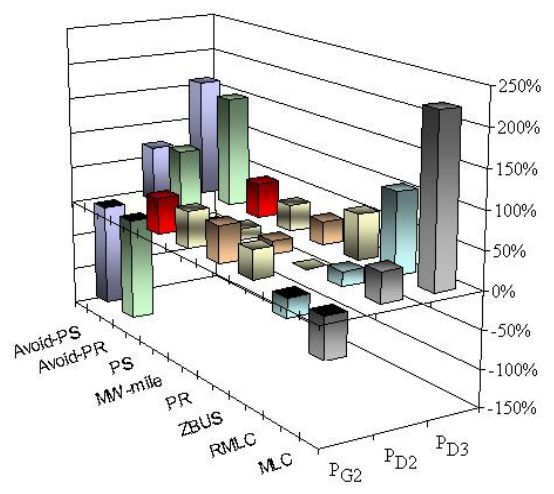

Fig. 3. Percentage of losses allocated for $\eta_{2}=50 \%$
Under approaches based on avoided costs, it is seen that generator 2 is rewarded with negative losses and both loads must pay for their contribution in loss increase. In Fig 3, it is seen that under penetration levels between $10 \%$ and $70 \%$, avoided procedures have great volatility behaving as a marginal approach.

\section{-- Social Welfare Evaluation}

Since demand behavior is dependent of energy prices, after the application of every loss allocation procedure is possible to obtain new operation points applying equations (39-41). Table IV presents the new operation points referred to each allocation procedure considering DG penetration of $50 \%$ in wind farm 2 .

TABLE IV

NEW OPERATION POINTS FOR THE EIGHT COMPARED LOSS ALLOCATION PROCEDURES WHEN DG PENETRATION $\eta_{2}=50 \%$

\begin{tabular}{|c|c|c|c|c|c|c|c|c|c|}
\hline \multirow{3}{*}{$\begin{array}{l}\text { Loss } \\
\text { Allocation } \\
\text { Procedure } \\
\end{array}$} & \multicolumn{2}{|c|}{ Production } & \multicolumn{2}{|c|}{ Demand } & \multirow{2}{*}{$\begin{array}{c}\text { Losses } \\
\mathrm{L} \\
\end{array}$} & \multicolumn{4}{|c|}{ Nodal Prices } \\
\hline & $P_{G 1}$ & $\mathrm{P}_{\mathrm{G} 2}$ & $\mathrm{P}_{\mathrm{D} 2}$ & $\mathrm{P}_{\mathrm{D} 3}$ & & $\rho_{\mathrm{G} 1}$ & $\rho_{\mathrm{G} 2}$ & $\rho_{\mathrm{D} 2}$ & $\rho_{\mathrm{D} 3}$ \\
\hline & \multicolumn{4}{|c|}{ (pu) } & $\mathrm{kW}$ & \multicolumn{4}{|c|}{$(\$ / \mathrm{MWh})$} \\
\hline MLC & 0.279 & 0.275 & 0.200 & 0.350 & 35.220 & 10.000 & 10.070 & 10.070 & 10.225 \\
\hline RMLC & 0.281 & 0.275 & 0.200 & 0.352 & 35.698 & 10.000 & 10.034 & 10.034 & 10.108 \\
\hline ZBUS & 0.282 & 0.275 & 0.201 & 0.353 & 35.904 & 10.000 & 9.951 & 10.002 & 10.061 \\
\hline PR & 0.282 & 0.275 & 0.200 & 0.353 & 35.994 & 10.000 & 9.936 & 10.032 & 10.032 \\
\hline MW-mile & 0.282 & 0.275 & 0.200 & 0.353 & 35.984 & 10.000 & 9.936 & 10.026 & 10.036 \\
\hline PS & 0.282 & 0.275 & 0.201 & 0.353 & 35.950 & 10.000 & 9.936 & 10.003 & 10.048 \\
\hline Avoid-PR & 0.279 & 0.275 & 0.199 & 0.351 & 35.437 & 10.000 & 10.179 & 10.154 & 10.154 \\
\hline Avoid-PS & 0.279 & 0.275 & 0.199 & 0.351 & 35.409 & 10.000 & 10.179 & 10.135 & 10.164 \\
\hline
\end{tabular}

The results indicate that reconciled procedures —as RMLC, Zbus, PR, MW-mile, PS, Avoid-PR and Avoid-PS procedures - derive in nodal prices lower than the prices obtained from MLC method. These conditions encourage an increase in load consumption as consequence of responsiveness of demand and therefore yield in an increase of power losses. In fact, maximum power losses were achieved under PR approach. Also, the lowest power losses were achieved under MLC approach and the highest under PR approach.

TABLE V

DiSTRIBUTION NETWORK REMUNERATION AND SOCIAL WELFARE

\begin{tabular}{|c|c|c|c|c|c|c|}
\hline \multirow{3}{*}{$\begin{array}{l}\text { Loss } \\
\text { Allocation } \\
\text { Procedure }\end{array}$} & \multicolumn{3}{|c|}{ Distribution Remuneration (cts\$/hr) } & \multicolumn{3}{|c|}{ Social Welfare $(\$ / h r)$} \\
\hline & \multicolumn{3}{|c|}{ DG penetration level $\eta$ (\%) } & \multicolumn{3}{|c|}{ DG penetration level $\eta$ (\%) } \\
\hline & $10 \%$ & $50 \%$ & $90 \%$ & $10 \%$ & $50 \%$ & $90 \%$ \\
\hline$\overline{\mathrm{MLC}}$ & 75.0129 & 38.186 & 39.2304 & 62.183 & 83.620 & 104.455 \\
\hline RMLC & -0.6061 & -0.2492 & -0.1198 & 62.937 & 84.003 & 104.848 \\
\hline ZBÜS & -1.5431 & -0.5117 & -0.2374 & 62.937 & 84.004 & 104.849 \\
\hline PR & -1.3623 & -0.6555 & -0.3601 & 62.941 & 84.005 & 104.848 \\
\hline MW-mile & -1.3775 & -0.6373 & -0.4160 & 62.940 & 84.005 & 104.849 \\
\hline PS & -1.3389 & -0.5817 & -0.2256 & 62.940 & 84.005 & 104.849 \\
\hline Avoid-PR & -0.4945 & -0.1562 & -0.5574 & 62.940 & 84.005 & 104.849 \\
\hline Avoid-PS & -0.4701 & -0.1053 & -0.4775 & 62.940 & 84.005 & 104.849 \\
\hline
\end{tabular}

The table $\mathrm{V}$ shows the distribution network remuneration (NR) and social welfare results (SW) computed using equations (44) and (43) respectively for the three DG penetration levels.

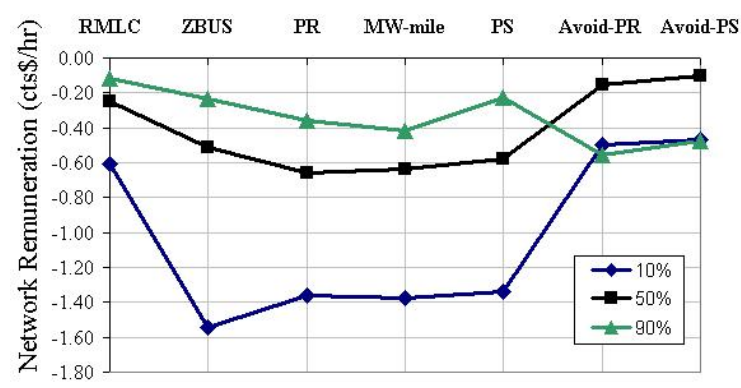

Fig. 4. Network remuneration for different DG penetration levels $\left(\eta_{2}\right)$. 
It is observed that the network remuneration behavior as function of $\eta$ is similar than presented by actual losses curve in Fig. 2. In fact, under MLC approach, the minimum NR value is achieved at same point $\left(\eta_{2}=69 \%\right)$. All reconciled procedures derive in negative remuneration values at similar social welfare level. As seen in Fig 4, only RMLC and Avoided methods were able to guarantee network remuneration near to zero for all DG penetration levels.

\section{B. Case $N^{\circ} 2$ : 28-bus network}

As shown in Fig. 5 a 28-bus $15 \mathrm{kV}$ distribution system is used to apply the proposed methodology. The test system comprises 25 demands and 2 wind farms connected at bus 27 and 28 respectively. Each wind farm has a generation capacity of $15 \mathrm{MW}$. Due to regulatory requirements both wind farms must generate reactive power (using VAR compensation, if required) in order to guarantee a nominal voltage level at their own busbar. Data line can be found in [10].

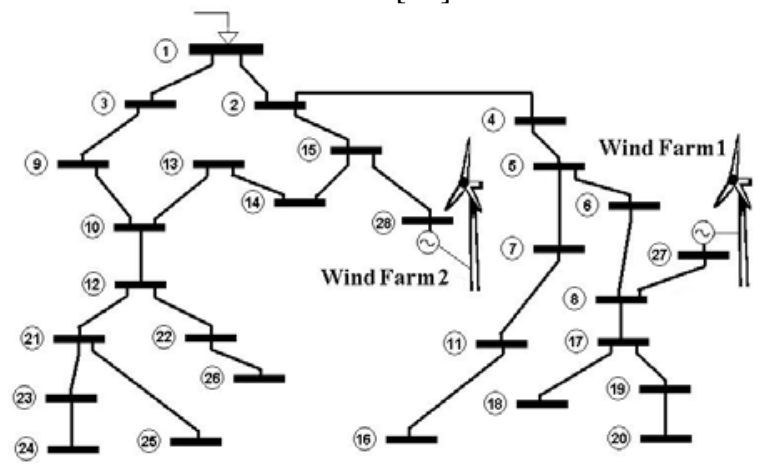

Fig. 5. 28-bus test network

\section{-- Market Equilibrium Point}

Transmission system is linked with the distribution network through the interconnection node (bus 1). Energy is purchased at wholesale market at clearing market price $\lambda_{\text {sys }}=30 \$ / M W h$. Regulation imposes that energy injected by the wind farms $P_{G 27}$ and $P_{G 28}$ are remunerated at the same clearing market price $\lambda_{\text {sys }}$. At equilibrium point total active and reactive demand are 15.5MW and 4.6MVAr respectively. All loads have price elasticity equal to -0.5 . For each penetration level, the initial operation point is fixed at the price results of MLC approach at the peak power load specified in the line data.

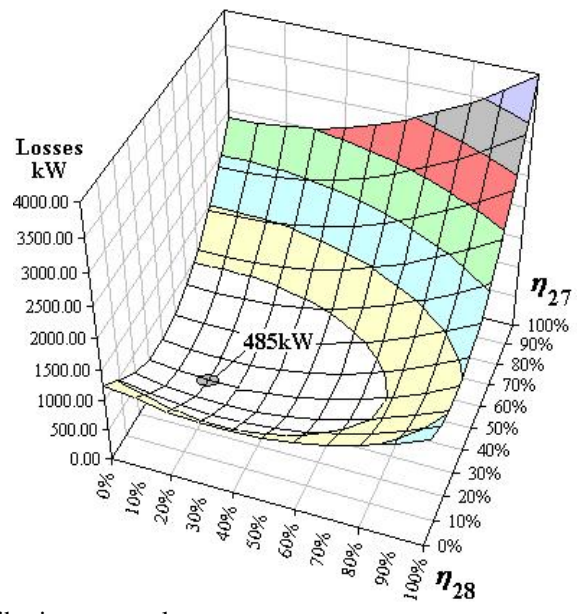

Fig. 6. Distribution system losses

\section{.- Power Loss Allocation and Social Welfare Analysis}

Fig. 6 shows the losses $L$ produced in the system by the interaction of both wind farms thought the DG penetration level computed using equation (47). For instance, $\eta_{27}=10 \%$ implies that wind farm connected at bus 27 injects $P_{G 27}=1550 \mathrm{~kW}$. The minimum losses in the system $(485 \mathrm{~kW})$ were reached when $\eta_{27}$ $=30 \%$ and $\eta_{28}=20 \%$. Also, it is achieved that power losses disregarding the impact of both wind farms are 1290kW. Fig. 7 shows the behavior of actual and avoided power losses as function of DG penetration levels

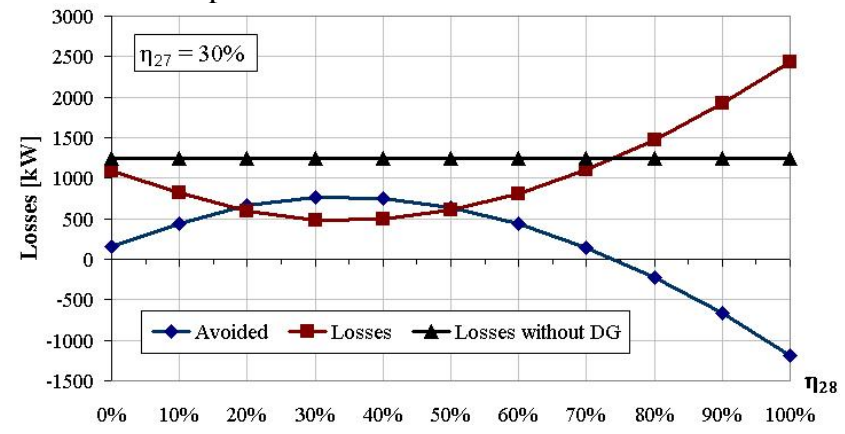

Fig. 7. Distribution Losses as function of $\eta_{28}$ when $\eta_{27}=30 \%$

It is seen that at given penetration levels, wind farms are not able to avoid power losses. For instance, when $\eta_{27}=30 \%$ and $\eta_{28}>75 \%$ actual power losses are greater than the losses without DG and avoided losses become negative. Due to lack of space, loss allocation results were not included in this paper. The social welfare and distribution network remuneration results were computed directly using equations (43) and (44) and seven combinations of DG penetration levels for both wind farms. Results are presented in Tables VI and VII.

TABLE VI

$$
\text { SOCIAL WELFARE }
$$

\begin{tabular}{l|cccccccc}
\hline \multirow{7}{*}{$\begin{array}{l}\text { Loss } \\
\text { Allocation }\end{array}$} & \multicolumn{7}{|c}{ Social Welfare $(\$ / \mathrm{hr})$} \\
\cline { 2 - 8 } Procedure & \multicolumn{7}{|c}{ DG penetration level $\eta_{27}(\%)-\eta_{28}(\%)$} \\
\hline MLC & 694.82 & 735.22 & 844.72 & 966.41 & 677.54 & 776.09 & 817.59 \\
RMLC & 709.56 & 748.65 & 861.03 & 999.93 & 703.28 & 792.35 & 867.58 \\
\hline ZBUS & 709.82 & 748.84 & 861.07 & 999.94 & 704.01 & 792.42 & 868.13 \\
PR & 709.88 & 748.92 & 861.12 & 1000.11 & 704.27 & 792.54 & 870.96 \\
MW-mile & 709.85 & 748.89 & 861.09 & 1000.04 & 704.17 & 792.54 & 871.19 \\
PS & 709.85 & 748.88 & 861.09 & 1000.10 & 704.13 & 792.51 & 870.25 \\
\hline Avoid-PR & 709.46 & 748.61 & 861.20 & 1000.54 & 703.44 & 792.96 & 871.63 \\
Avoid-PS & 709.52 & 748.67 & 861.26 & 1000.60 & 703.05 & 793.47 & 873.11 \\
\hline
\end{tabular}

Similarly to the previous case, MLC procedure derives in high volatile prices with a considerable loss of social welfare respect to reconciled procedures. In addition, it is important to refer that social welfare grows when the penetration level is increased due to the low marginal cost of renewable energy. The social welfare is improved when high cost energy purchased at the market is substituted by renewable energy.

Minimal power losses were achieved using the MLC pricing framework. This approach leads in the competitive prices that send the correct economic signals to all market agents yielding on full-powered incentives for cost loss minimization. However, these prices produce high price volatility and a considerable loss of social welfare as product of positive network remuneration. For all penetration levels, it is noticed that reconciled procedures are unable to ensure revenue reconciliation of losses. 
TABLE VII

DISTRIBUTION NETWORK REMUNERATION

\begin{tabular}{|c|c|c|c|c|c|c|c|}
\hline \multirow{3}{*}{$\begin{array}{l}\text { Loss } \\
\text { Allocation } \\
\text { Procedure }\end{array}$} & \multicolumn{7}{|c|}{ Distribution Remuneration $(\$ / \mathrm{hr})$} \\
\hline & \multicolumn{7}{|c|}{ DG penetration level $\eta_{27}(\%)-\eta_{28}(\%)$} \\
\hline & $30 \%-10 \%$ & $30 \%-20 \%$ & $30 \%-50 \%$ & $30 \%-90 \%$ & $10 \%-20 \%$ & $50 \%-20 \%$ & $90 \%-20 \%$ \\
\hline MLC & 14.5668 & 13.2930 & 16.2378 & 33.4796 & 25.1810 & 16.1947 & 49.5004 \\
\hline RMLC & -0.3642 & -0.2907 & -0.1478 & -0.0725 & -1.1853 & -0.1344 & -1.0308 \\
\hline ZBUS & -0.9074 & -0.6815 & -0.2370 & -0.0875 & -2.7401 & -0.2841 & -2.1789 \\
\hline PR & -1.0323 & -0.8350 & -0.3442 & -0.4317 & -3.2945 & -0.5236 & -8.1314 \\
\hline MW-mile & -0.9753 & -0.7805 & -0.2717 & -0.3056 & -3.0749 & -0.5297 & -8.6160 \\
\hline PS & -0.9745 & -0.7718 & -0.2817 & -0.4070 & -2.9888 & -0.4800 & -6.6320 \\
\hline Avoid-PR & -0.1581 & -0.1885 & -0.4979 & -1.3315 & -1.5180 & -1.4282 & -9.5215 \\
\hline Avoid-PS & -0.2820 & -0.3159 & -0.6365 & -1.4856 & -0.7077 & -2.4954 & -12.6477 \\
\hline
\end{tabular}

As seen in Fig. 8, the best performance was achieved under RMLC approach and the worst under PR approach.

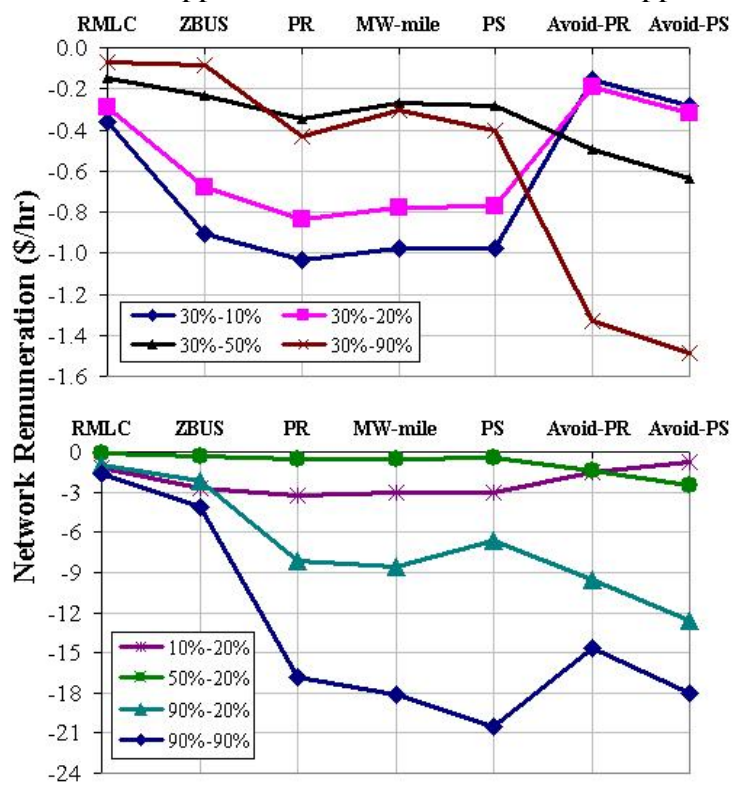

Fig. 8. Network remuneration for different DG penetration levels.

Unlike transmission system due to practical reasons the distribution-reconciled procedures (Zbus, PR, PS and MWmile) based in 50:50\% allocation require a reference bus definition at interconnection point of distribution network. This result implies that an arbitrary loss distribution sending wrong economical signals to the market agents.

Finally, it is important to point out that the two approaches based on avoided cost criteria yield in good solutions when they are near to the optimal DG penetration. At this point, avoid cost procedure behaves as a marginal approach.

\section{CONCLUSION}

This paper introduces a novel analysis for the regulatory evaluation of the impact of different loss allocation procedures. The assessment of different distribution access-pricing methodologies applied under liberalized energy markets is based on the social welfare theory and it must take into account the effect of price elasticity of demand. The convenience in the application of a full marginal loss allocation method (MLC) or different reconciled procedures (RMLC, Zbus, PR, MW-mile, PS and Avoided cost methods) could be summarized in a set of results with advantages and drawbacks:

- The application of a full marginal procedure yields in the competitive prices. These prices are the correct economic signals to all market agents sending full-powered incentives for cost loss minimization. However, these prices produce high price volatility and a considerable loss of social welfare as product of positive network remuneration.

- The application of reconciled marginal procedures under an elastic and efficient energy market does not recover the cost of the entire of power losses. The best performance was achieved under RMLC approach and the worst under Pro Rata approach. All approaches derive in an increase of power losses respect to the competitive solution (MLC).

\section{REFERENCES}

[1] A. J. Conejo, J. M. Arroyo, N. Alguacil and A.L. Guijarro "Transmission Loss Allocation: A Comparison of Different Practical Algorithms,” IEEE Trans. Power Systems, vol. 17, no. 3, pp. 571-576, Aug. 2002.

[2] J.R. Saenz, P. Eguia, J.L. Berastegui, J. Marin and J. Arceluz "Allocating Distribution Losses to Consumers Using Distribution Loss Factors" in Proc. of IEEE Porto PowerTech 2001, vol. 1, pp.1-4, Sept. 2001.

[3] D. Shrimohammadi, X. V. Filho, B. Gorenstein and M.V.P. Pereira, "Some fundamental technical concepts about cost based transmission pricing," IEEE Trans.Powe rSystems, vol. 11-2,pp.1002-1006,May 1996.

[4] J.W. Bialek, "Tracing the Flow of Electricity," IEE Proc-Gener., Transm., and Distrib., vol. 143, pp. 310-320, Jul. 1996.

[5] A. J. Conejo, F.D Galiana, and I. Kockar "Z-bus Loss Allocation,” IEEE Trans. Power Systems, vol. 16, no. 1, pp. 105-110, Feb. 2001

[6] A. J. Wood and B. F. Wollenberg, Power Generation Operation and Control: Wiley-Interscience Publication, 1996.

[7] P.M. De Oliveira-De Jesus and M.T. Ponce de Leão "Cost Loss Allocation in Distribution Networks with Embedded Generation: A Fuzzy Approach" Proceedings of MEDPOWER 2004, Lymassol, Cyprus, Nov., 2004. [

[8] N. Hatziargyriou, T. Karakatsanis and K. Papadogiannis "Probabilistic Cost Allocation of Losses in Networks with Dispersed Renewable Generation" PMAPS 2002, Naples, pp. 519-524, Sept., 2002

[9] J. Mutale, G. Strbac, S. Curic and N. Jenkins "Allocation of losses in distribution systems with embedded generation," IEE Proc-Gener., Transm., and Distrib., Vol. 147, No. 1, pp. 7-14, Jan., 2000.

[10] J.A. Peças Lopes, A. Mendonça, N. Fonseca and L. Seca "Voltage and reactive power control provided by DG units" in Proc. Power Systems with Distribution Generation CIGRE Symposium, Athens Greece, 13-16 April 2005.

[11] P.M. Costa and M. Matos "Loss allocation in distribution network with embedded generation,” IEEE Trans Power Systems, Vol.19 No.1, pp 384389, Feb. 2004

[12] S. Stoft, Power System Economics, Piscataway NJ: IEEE - Wiley Interscience Publication, 2002

[13] P.M. De Oliveira-De Jesus and M.T. Ponce de Leão "Impact of uncertainty and elastic response of demand in short term marginal prices," in Proc. of PMAPS2004, Iowa, Sept. 2004.

[14] F. C. Schweppe, M. C. Caramanis, R. D. Tabors and R. E Bohn, Spot Pricing of Electricity, Boston MA: Kluwer Academic Publishers, 1988.

[15] W. Nicholson, Microeconomic Theory, $7^{\text {th }}$ Edition, New York: The Dryden Press, pp. 440-441,558, 1997.

\section{BIOGRAPHIES}

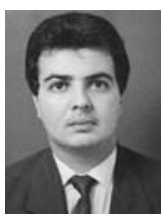

P. M. De Oliveira De Jesus (M’03) He received the M.Sc. and the Electrical Engineering degree, in 2002 and 1995, from Universidad Simón Bolívar, Caracas, Venezuela. Former Assistant Professor of Electrical Engineering at Universidad Simón Bolívar, he is presently pursuing Ph.D. studies at Faculdade de Engenharia da Universidade do Porto (FEUP) and work as researcher of the Instituto de Engenharia de Sistemas e Computadores (INESC Porto), Portugal.

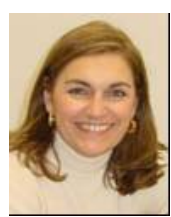

M. T. Ponce de Leão (M’95) She got her degree and Ph.D. degree from Faculdade de Engenharia da Universidade do Porto (FEUP) in 1980 and 1996. Currently, she is Professor in the Electrical and Computer Department of FEUP. Since 1987, she works at the Instituto de Engenharia de Sistemas e Computadores (INESC), as researcher. In recent years she was involved in the development of DMS systems and in the evaluation of impact of distributed generation in distribution planning. 